\title{
Valuable but Flawed: Stakeholder Perceptions of the Ontario Mandatory Community Involvement Program
}

\author{
Barbara Harrison \\ Brock University
}

\begin{abstract}
The purpose of this study was to explore the experiences of five groups of people-students, parents, community organization representatives, guidance counselors, and principals - in dealing with a community involvement requirement for secondary school graduation in Ontario. Ten people were interviewed, resulting in insights as to what makes the program work for the various groups, and suggestions for improvement. Interviewee recommendations include creating a more structured program to increase the consistency of program implementation, reducing the administrative burden on schools, increasing the number of required hours, and having more support for the program from the Ontario government and the Ontario Ministry of Education.
\end{abstract}

In 1999 the Ontario Ministry of Education introduced a new graduation requirement for secondary school students--40 hours of community "involvement" (Ontario Ministry of Education, 1999a, p. 9). According to the Ontario Ministry of Education this involvement consists of community service to be performed in places of the student's choice, as long as the work is not paid work, replacing paid work, or part of a course for which the student would obtain a credit. The Ontario Ministry of Education notes that the intention behind this educational requirement (which is often referred to as "the program" in this article) is to "encourage students to develop awareness and understanding of civic responsibility and of the role they can play in supporting and strengthening their communities" (Ontario Ministry of Education, p. 9).

Although the Ontario Ministry of Education refers to civic responsibility, the documents outlining this program do not provide a definition for the term. Also missing is an explanation of how mandated involvement in the community will result in students gaining an enhanced sense of their civic responsibility or a deeper understanding of their role and impact in the community. It is assumed by the Ontario Ministry of Education that community involvement will benefit both students and the "community", a term it does not define; however, the primary purpose of this program is to contribute to students' development (Ontario Ministry of Education, 1999a, p. 9). To date there is little published work on the effectiveness of the program, and the Ontario Ministry of Education has not undertaken their own study. (Brown, Pancer, Henderson \& Ellis-Hale, 2007; 
Livingstone, 2006; Meinhard, Foster \& Wright, 2006; Ontario Network-Canada Volunteerism Initiative (OCVI), 2006a).

As a parent of two daughters who have been involved in fulfilling this 40 hour requirement I have had a personal interest in the broader application of this program. My daughters attended different schools, one private and one public. One of the schools emphasized this program and the other did not, allowing me to observe how two schools in the same city interpreted the program in very different ways. As a result of our experiences I became interested in how other stakeholders perceived the effectiveness of this program. The purpose of this study is therefore to explore the experiences of a sampling of the primary stakeholders who are part of the community involvement process. Mandated policies are controversial, in that there are always people who are for and against a requirement. From the perspectives of the interviewees, this study highlights what is working and not working within the current guidelines of the Ontario 40 hour program. It also makes recommendations for how this program could be enhanced. Although this study is small, the feedback from the participants provides another source of information to the literature on the effectiveness of the Ontario Ministry of Education's community involvement program.

\section{Literature Review}

Several authors have pointed to the value of involvement in one's community as a way to strengthen the community and oneself (for example, Brown, Pancer et al., 2007; OCVI, 2006a). Brock and Bulpitt (2007), two Canadian authors, note that "high levels of voluntary activity promote a general sense of social responsibility, build social ties and contribute to a healthy society, variously defined, as well as to individual mental and physical health" (p. 4).

Yet despite these benefits to volunteers, the 2004 National Survey on Giving, Volunteering and Participating, produced by Statistics Canada, showed that the top quarter of volunteers (11\% of Canadians) contributed over $77 \%$ of the volunteer hours (Hall, Lasby, Grumulka, \& Tryon, 2006). Charitable and nonprofit organizations are therefore highly dependant on a small group of volunteers.

The 2000 National Survey on Giving, Volunteering and Participating found that $37 \%$ of youth aged 15-24 years were volunteering their time (Canadian Centre for Philanthropy, 2003). In the 2004 Canada Survey of Giving, Volunteering and Participating, this number had increased to $55 \%$ of youth aged $15-24$ years, which included "volunteering" in mandatory programs such as the one in Ontario (Hall et al., 2006, p. 42). According to the 2004 statistics, youth volunteers accounted for $17 \%$ of total volunteer hours, of which 106 million hours were contributed by youth volunteers in mandatory community service programs (Hall, et al.). Although statistics show an increase in youth volunteering, the authors note that, on average, youth involved in mandatory programs contributed the same number of hours as those youth not mandated to do so. 


\section{The Ontario Community Involvement Program}

In a study of Canadian secondary school community service programs, Brown, Meinhard, Ellis-Hale, \& Henderson (2007) found that almost all of the provinces and territories have community service programs of some sort, and that six of the 13 governments have introduced community service as a requirement for graduation. Ministries of Education in Canada appear to have done little to invest in these programs to maximize their potential (Brown, Meinhard, et al.). The authors note that each Canadian province and territory oversees its own education system, which results in variations in educational requirements from province to province.

According to Brock (2001, p. 56), the Ontario community involvement program emerged from recommendations of the 1994 Royal Commission on Learning and the 1997 Premier's Advisory Board, where the former stressed the need for schools and communities to have stronger links, and the latter recommended that the government introduce voluntary action learning (or community service) and that the course be implemented as either a compulsory or voluntary credit for high school graduation. The community involvement program is also said to have been inspired by somewhat similar programs in British Columbia and the United States (McLeod \& Nicholson, 1998). U.S. programs are sometimes government funded or can have financial incentives for students built in, and many require substantially more than 40 hours of community service (McLeod \& Nicholson). The Ontario program does not include funding of any type (McLeod \& Nicholson), and the process for determining that 40 hours was the right number of hours has not been made apparent.

The Ontario Ministry of Education outlined the objectives for the program, including some of the stakeholder responsibilities, in both the official document that outlines secondary school graduation requirements (1999a) and in Memorandum 124a (1999b), which deals with the application of this program. According to the Memorandum, boards are to develop forms to record eligible activities and to provide a booklet to students that explains the program and outlines eligible/ineligible activities. The Ministry provides sample forms as a guide. Principals are to ensure that the requirement is described in the school calendar, to determine if students have met the criteria, and to make any discretionary decisions regarding the eligibility of service activities. The Memorandum outlines overall procedures for students (mostly administrative in focus) and advises that students are to pass on copies of program documents to their parents and community involvement "sponsors". Typical eligible activities include volunteering for a non-profit or public sector organization in various capacities, assisting with fundraising activities, and assisting with school-based activities approved by the school principal, with the stipulation that the involvement must not lead to a credit (Ontario Ministry of Education, 1999a, 1999b).

The Ontario community involvement program was introduced without giving schools much time to prepare for the additional administrative responsibilities involved. It was part of a larger curriculum reform process that reduced secondary school in Ontario from five years to four, with the corresponding curriculum content changes (Henderson et al., 2007; Meinhard, Foster \& Wright, 
2006). Hence schools and school boards were under a lot of pressure to accommodate the new requirements, and it is possible that the community involvement requirement was given less focus by school boards than the curriculum changes.

Allmendinger (2006) surveyed 10 boards in Ontario and found that not one of them fully complied with the document requirements in the Ontario Ministry of Education's (1999b) outline. She also found vast differences in implementation between school boards and between schools, as did Brown, Meinhard, et al. (2007). Several authors conclude that there is a need for more clarity on the implementation of this program (for example, Allmendinger, 2006; Meinhard et al., 2006). Research on the Ontario program has found that the majority of students surveyed felt that their community service experiences had been beneficial (for example, Brown, Pancer, et al., 2007; Meinhard et al., 2006; OCVI, 2006a). However there are moderating factors. The program's design emphasizes the fulfillment of hours rather than the need for meaningful involvement (Meinhard et al., 2006; Pupo, 2004). Some students leave their community involvement until Grade 12, when there is a scramble to complete the hours in order to graduate (Livingstone, 2006; Padanyi, Meinhard \& Foster, 2003) Authors such as Meinhard et al. (2006) raise a concern that 40 hours may be too heavy a requirement for students to fulfill in addition to their part-time jobs, extracurricular activities, and family responsibilities. There is also a concern that some students might have easier access to community service opportunities than others ((Livingstone, 2006; Pupo, 2004). Overall Meinhard et al. (2006) found that if the program was challenging, incorporated student input, and had variety and opportunities for reflection, it was more meaningful.

The mandatory nature of this and other programs in the United States and Canada has been a source of discussion in the literature (for example Brock, 2001; Brown, Pancer, et al., 2007; Livingstone, 2006; Meinhard et al., 2006; Metz, McLellan, \& Youniss, 2003, Metz \& Youniss, 2005; OCVI, 2006a, 2006b). The concern has been whether making "volunteering" mandatory discourages youth from future volunteering. The researchers question whether it is in fact possible to mandate volunteering when the essence of being a volunteer is that one freely gives of one's time and skills. In general the literature has held that the mandatory nature of the program is not a deterrent to future volunteering.

In summary the literature on both mandated community service in general, and on this program in particular, suggests that there are advantages and disadvantages to this type of graduation requirement. The literature on the Ontario program makes recommendations for enhancing the program, none of which appear to have been implemented by the Ontario Ministry of Education.

\section{Method}

This study incorporated a narrative inquiry approach (Clandinin \& Connelly, 2000), using a semi-structured interview process. Narrative inquiry focuses on "experience as the phenomenon under study" (Connelly \& Clandinin, 2006, p. 477) and emphasizes the sharing of stories, both the researcher's and those of the participants (Clandinin \& Connelly). This study sought to explore the experiences of a selection of students, parents, school principals, guidance counsellors (as they generally administer the school's part of this program) and 
community organization representatives in dealing with a community service graduation requirement in Ontario. A sample of 10 people in total was chosen for this research, two people representing each of the primary stakeholder groups involved with this program. All of the school employees and the students in this study came from the same school board in Ontario. The participants were sourced through a "snowball" technique, where participants assisted me in locating the stakeholders in this study. In the interview process it was discovered that both community organization representatives and one of the guidance counsellors had also experienced this program as parents of high school students, and they therefore commented on the program from dual points of view. Pseudonyms are used when naming participants.

\section{Data Analysis}

Clandinin (2007) notes that there are generally two ways that narrative analysis is conducted, which she terms "narrative analysis and analysis of narrative" (p. xv). The first constructs a representative narrative from the stories in the study. The second analyzes stories as data, finding "common themes, metaphors, plot lines and so on to identify general themes or concepts" (Clandinin, 2007, p. Xv). This study employed the second method. I transcribed the interviews then coded the data by categories. These categories were determined through looking for meaningful themes or "recurring patterns: that cut across the data in the interviews" (Merriam, 1998, p. 179). Once the data were analyzed, the findings were related back to the studies of Brown, Pancer, et al (2007), Livingstone (2006), and the Ontario Network-Canada Volunteerism Initiative (OCVI, 2006a) in order to assess how these findings fit with the existing literature on the 40 hour program.

\section{Limitations}

The major limitations of this study are its size, and that it represents a sampling from only one school board in Ontario. As a result of the limited scope of the study the results cannot be said to represent broader populations, although the data are valuable as they represent the experiences of this particular group in dealing with the program. They provide stakeholder feedback that could inform the direction of a larger study. While I have referred to the groups in this study as the stakeholders of this program, others may argue that these groups are not the only stakeholders in the program. In using interviewing as the sole method of data collection, which in itself is a limitation of this study, the substance for this research was based on participant self-report. As a narrative researcher the world view of the participants, in relation to mine, is seen as an important aspect of understanding how these stakeholders experienced the Ontario program. It is possible that other researchers may see self-report as a limitation of this study.

\section{Findings and Discussion}

The participants in this study noted that high school students are involved in a range of community-based activities as part of fulfilling the program requirement. These activities included helping to run children's activities or sports programs, picking up litter, helping at charity fundraising events, assisting 
with church activities, visiting seniors, walking guide dogs in training, and generally assisting non-profit and public service organizations in implementing their programs.

Overall the interviewees felt that this was a meaningful program, due to what they perceived as the benefits of the program, but the extent to which they embraced the program differed in degree. Even though they favoured the program they saw opportunities to strengthen it.

\section{Benefits of the program}

Peter, a high school guidance counsellor, summed up his feelings, and in effect those of the majority of the stakeholders interviewed, by saying "I think it's a meaningful program. I think it's an opportunity for students to experience what it means to be a positive, contributing citizen. It encourages empathy and compassion in kids."

The parents and community representatives felt that the program had been beneficial. For example, Liz, a parent of two high school graduates and a community organization representative who works with school volunteers, stated that the community involvement program had been an asset in terms of enhancing the programs and services that could be offered by her organization. She also felt it had benefitted her two daughters.

Four of the participants mentioned that the program provided opportunities that took students outside their comfort zone. Students had experiences working with people or groups with which they might not otherwise have been involved. They were often placed in situations that were totally new to them, such as working with seniors in a retirement home.

Students were sometimes encouraged to see the requirement as a personal benefit. For example, one of the guidance counsellors noted that for students in grade 12 these experiences are significant for scholarship applications or to satisfy entry requirements for programs like teacher education, where community service can help applicants to stand out. He saw it as "showing the balanced and well-rounded candidate." At some of the schools and community placements, students were recognized in various ways for their number of volunteer hours and contributions in their service placement(s).

Five of the participants mentioned that these service experiences act rather like a first job experience, as students tend to complete their hours before being old enough to work in a paid position. The community involvement became an experience to add to the resume. The service experiences gave students the opportunity to try out work settings and duties that might relate to future career choices. The experiences potentially highlighted what they they might pursue further, or avoid.

All of the stakeholders saw the experiences as a means to gaining new skills and a source of personal growth. Most often the skills gained, attributed directly or indirectly to this program and subsequent volunteering, were leadership skills, enhanced communication skills, better time management, and an ability to work with different types of people and accommodate their needs. Four of the participants (the two parents and two community representatives who were parents themselves) noticed an increased level of self-confidence in the students. 
Although the program was seen to be meaningful overall, several participants noted what they saw as drawbacks to the program. For example, Ken, a high school principal, acknowledged that he felt "ambivalent" about the program in that he supports the spirit of the program, but not the way it has been structured. He found that students who had previously helped around the school anyway were now looking to have those activities documented as "hours", having it count towards their requirement. He believed that giving hours for these tasks, which he would do in spite of his belief, is not in keeping with promoting service to the broader community, which he thought was the intent of this program.

Several of the participants felt that the mandatory nature of the program meant that students often complete the hours merely as a requirement and did not gain from it. Tara, a student, noted that many students "just go do it and stop when they get to 40." This comment reflected a common concern expressed by most of the stakeholders; they questioned the extent to which this program makes a difference, although when asked about the effect of the program on themselves or their school they usually felt that it had been positive.

Participants outlined factors that they felt impede the program's success. Their critique fell into three main categories that largely related to 1) the loose structure of this program, 2) administration issues, some of which resulted from the loose structure, and 3) the need for more effective communication. These areas were found to overlap, and therefore the discussion of structure and administration will be combined into one section, followed by the often relating communication challenges.

\section{Structure and administration}

This program appears to be implemented unevenly. Although the Ontario Ministry of Education (1999b) outlined that the program is the responsibility of students and their parents, it appeared from the data in this study that some schools actively promote this program, encouraging students to get involved in community activities, and they recognized the students who exceeded their 40 hours. Other schools merely collect the proof of the hours spent and follow-up with students who are in danger of not graduating due to a lack of community service hours. Either way it involves additional administration for school personnel. It was noted that when students change schools there can be problems as schools have differing interpretations on what activities constitute fulfillment of the requirement, and each school board has its own requirements for documentation.

As with the principals, the two guidance counsellors in this study differed in their approach and attitude towards the program. One felt that the fulfillment of this requirement was a parental responsibility and it was not up to the guidance counsellors to approve the volunteer choices. She emphasized getting the hours completed rather than focusing on the experience or outcomes. She would tell students to "get it done by the end of grade 10 because by grade 11 you'll want a paid part-time job." The other guidance counsellor was more active in promoting the program, going out to the school's feeder schools and highlighting the service program to grade 7 and 8 students, and then actively promoting the program and its benefits once they got to high school. 
From the principals' and guidance counsellors' perspectives, several administrative issues were seen to stem from the loose structure of the community involvement program and what they perceived as insufficient communication from the Ministry of Education or the local school board on aspects of the program. Ken, a school principal, said

I think [the Ministry] should come out with stricter criteria on how you get your 40 hours. Right now it's all over the place...I know there was a list furnished to all of us of what's acceptable and not acceptable but a lot of [students] just go out and do whatever, and we're not sure what they're doing, or how legitimate it is.

The need for more structure and Ministry guidance in the program was mentioned by almost all of the participants. Guidance counsellors also have to deal with another administrative issue related to this program, namely cheating or attempts to circumvent the requirements or spirit of the program. Due to time constraints, and perhaps their perception of their role in this program, the schools in this study did not generally follow up to determine the validity of the documents presented as evidence of hours spent, although they acknowledged that a small percentage of students were likely cheating. Pam, a guidance counsellor, had occasionally questioned the nature of the student placement, and related a story of where the parent got involved and came in "yelling and screaming and called [her] a cheater and a liar and all sorts of things." She felt that "some parents just want their kids to be done with it and that's it."

Both guidance counsellors told of situations where the parents had seemingly been involved in circumventing the spirit of this program by representing that their child had completed hours that had not in fact been completed. These issues may stem from a lack of understanding of the requirements of the community involvement program or from deliberate abuse of the program. As with schools and parents, it is likely that there is a difference in how various community organizations work with students who are fulfilling the requirements of this program. In this study both organizations had actively embraced the program and had created a structure and expectations to maximize the student experience. Community organizations, however, can also be participants in undermining the intent of this program. For example, Tara, a student, gave an example of her dance school offering their students service hours, with the rationale that they were frequently at dance classes and possibly didn't have time to complete their community involvement hours.

\section{Communication}

Related to the above findings, communication was a theme that emerged in this study. While the principals and guidance counsellors in this study felt that they communicated effectively about this program, the results of this study suggest that this program is not well understood by stakeholders outside the school system. It appears that in general the communication from the schools was either too minimal or not necessarily effective. The guidance counsellors felt that parents often appear to get involved only when there is a problem in the placement or when the student is in danger of not fulfilling his/her 40 hours 
before graduation. Both of the parents in this study mentioned that they were not provided with guidelines as to what would make an eligible placement. This lack of clarity can result in situations where students have gained hours through working in their parent's business (which the Ministry's guidelines do not allow) or where students are working for a company that is clearly a for-profit business, such as a bank or hairdressing salon, and the school disallows the hours for the program. Although the Ministry's guidelines appear to allow the communitybased hours to be completed in a for-profit business, the school personnel interviewed had interpreted the program as requiring hours to be contributed to non-profit organizations only.

There also appears to be little communication between schools and community organizations. The general consensus, when talking to principals and guidance counsellors, was that community organizations tended to approach the school only if they were looking for student volunteers or had a problem with a student.

\section{Discussion and Implications}

The data from this study suggest that there are many potential benefits to the program. On a personal note, the findings of this study support, and expand on, my family's experiences of this community involvement program. I too received no information on this program from the public school that my daughter attended, a school which was in the same school board as the other schools in this study. I received more information from the private school, but never in relation to the mandatory requirement. In the private school the community service was positioned as being part of the schooling experience. Both of my daughters exceeded their 40 hours of community service. I believe they would have volunteered anyway, but the program provided them with leadership opportunities and had them contribute to organizations that were important to them.

This study was small, however, the findings further supported those of several studies that have found that the mandatory nature of a program does not seem to negate the positive outcomes of the experience (Brown, Pancer, et al., 2007; Henderson et al., 2007; Metz \& Youniss, 2005; Meinhard et al., 2006). At least one representative of each of the stakeholder groups commented that it seemed incongruous to mandate "volunteering," but they still thought the program was worthwhile despite that. This study found, as Brown, Pancer, et al., 2007; Henderson et al., 2007 and Padanyi et al. (2003) found, that this program had students "volunteer" where they might not otherwise have done or had them "volunteer" more hours than they might have. All of the participants in this study knew of students (or were themselves students) who had gone well beyond their 40 hours of service. Overall the interviewees' experience of the program had been positive.

Several stakeholders in this study wondered if the students would have volunteered anyway if this program had not been in place. For many of the stakeholders, volunteering appeared to be a core family value. One might therefore question if this program is a necessary part of the graduation requirements. It was uniformly mentioned that the 40 hours required by this program is too low. Six participants noted that these hours tend to be completed 
by the end of grade 10. For example, Tara, a student, noted "I haven't talked to anyone who has said I can't finish it. Especially if you break it up every year. It's 10 hours a year. That's nothing." Another recurring suggestion was that the service program should start at a younger age, which may also increase the number of hours involved. It was felt that young people are ready to volunteer at a younger age and the program should take advantage of that. In addition, Peter, one of the guidance counsellors, suggested that the program should not stop at the end of high school, so that youth are encouraged to keep volunteering in their community.

One of the critiques of this mandatory program, mentioned by each of the school principals, guidance counsellors and parents in this study, is that the Ontario Ministry of Education has left the program too unstructured. This lack of structure is seen to allow too much room for individual board and school interpretation, leading to a lack of consistency, differences in understanding, and gaps. These findings support those from other research that reached similar conclusions on the shortcomings of the present structure (e.g. Allmendinger, 2006; Brown, Meinhard, et al., 2007; Meinhard et al., 2006; OCVI, 2006a). It is of some concern that parents are seen to be key to this program, as reflected in the Ministry's written documentation, and yet appear to be peripheral in terms of the communication regarding the requirement. According to the program's design, schools are not generally involved in the application of this program, other than to keep records and deal with problems. It may be that the Ontario Ministry of Education, school boards and schools are assuming that parents are involved in assisting their children in finding and selecting volunteer opportunities, but parents are not necessarily aware of their assumed role and responsibilities. As a result students could be compromised, and the potential of this program could go unfulfilled.

\section{Recommendations}

There have been several recommendations in the Ontario-based literature that deal with the detracting aspects of this program (Allmendinger, 2006; Brown, Meinhard, et al., 2007; Brown, Pancer, et al., 2007; Henderson et al., 2007; Meinhard et al., 2006; T. Taylor and Pancer, 2007). The participants in this study raised similar recommendations. These recommendations include restructuring the program, streamlining administration, requiring more hours, improving communication between stakeholders, and more endorsement and support from the Ontario Ministry of Education and the school boards. The recommendations would serve to strengthen the existing program, and would address some of the burden of the program's administration on the schools.

More clarification and support from the Ontario Ministry of Education and school boards would assist educators in the administration of the program as well as provide clearer guidance to students seeking community placements. It would also potentially decrease the negative interactions between educators and parents, as stakeholders would be better informed on the elements of this program, potentially addressing the unintended consequences of this program.

Four stakeholders mentioned that developing closer relationships between community groups and schools would strengthen the program. Stronger partnerships could exist between schools and community agencies, between 
parents and the school, and between the Ontario provincial government in general and the Ontario Ministry of Education in particular in supporting schools as they administer this program. Through partnerships, communication could be improved, and the potential of the program could be deepened.

None of the research that I was able to locate specifically focused on the experience of community organizations working with mandated youth in Ontario, and this would be an area for future research. As Liz, from one of the community organizations, expressed it, "it's a lot of time and effort, and sometimes you measure it out and think...is this good value?" The two community organization representatives in this study felt that in the final analysis the involvement with this program is good value, and their conclusion mirrored that of most, if not all, of the stakeholders in the study.

It would be valuable for the Ontario Ministry of Education to consider transforming this program into a curriculum-based requirement, perhaps in the form of service-learning. Service-learning combines service to the community with curriculum and community-based learning, along with critical reflection to assist students in articulating and deepening their learning. The community service becomes an experiential opportunity for learning and an additional means to cover the instructional content (Billig, 2007). It adds relevance to what is learned in the classroom. The community involvement requirement would then be implemented within a credit course, for example the required Grade 10 Civics course, led by a teacher and perhaps incorporating a group community service opportunity. Within the classroom setting students would have time to reflect, discuss, and absorb what they have seen and done, and what it means to them. Students could have input on the nature of the community service opportunity, with the teacher there as the guide.

There are many studies that show the effectiveness of service-learning in K12 settings and beyond. Bradley (2005), for example, conducted a meta-analysis of service-learning programs, finding results such as: improvements in achievement tests, an enriched academic environment with more relevant learning, improved school climate, increased teamwork and cohesiveness, decreased student behavioural problems, significant improvement in behaviour, and opportunities for character development. Therefore it is possible that in addition to addressing several of the drawbacks of the current program, servicelearning could enhance the learning gained from this requirement, as well as being of value to the community by filling real needs. A service-learning course lead to the fulfilment of the underlying objectives of the community involvement requirement.

\section{Conclusion}

The concept of community involvement, or community service, as part of formal education is not new. John Dewey (1916/2005), for example, argued that community service is a key component of education. As one of the principals in this study mentioned, students have always been involved in community service activities within the school and in their broader communities, but this program provides an incentive for those students who might not have otherwise got involved in community service. It potentially introduces students to community groups and community-based opportunities that they might not otherwise have 
known about. Many students go on to contribute far more than the mandated 40 hours, which is the program's overall goal. As a parent, teacher and community member my hope is that the Ontario Ministry of Education heeds the recommendations in the literature on this program, and looks for ways to strengthen this graduation requirement.

This study sought to provide further input to the literature on the Ontario Community Involvement requirement through the experiences of a sample of stakeholders in a particular school board in Ontario. Although the stakeholders endorsed the program, they did so with reservations related to its structure and application rather than to its intent. With refinement this program has the potential to become a powerful option for learning and community service, and could become a means of engaging students in both their studies and in making a difference to our communities. As presently designed this program has value, but it is flawed.

\section{References}

Allmendinger, C. (2006). Ontario's secondary school community involvement diploma requirement: A descriptive study of the program and its implementation. Unpublished Master of Education Thesis, Queen's University, Kingston.

Billig, S. H. (2007). Unpacking what works in service-learning: Promising research-based practices to improve student outcomes. In Growing to greatness 2007: The state of servicelearning project (pp. 18-28). St. Paul, MN: National Youth Leadership Council.

Bradley, L. R. (2005). K-12 service-learning impacts: A review of state-level studies of servicelearning. In Growing to greatness 2005: The state of service-learning project (pp. 41-47). Saint Paul, MN: National Youth Leadership Council.

Brock, K. L. (2001, Summer). Promoting voluntary action and civil society through the state. Isuma, 53-61.

Brock, K. L., \& Bulpitt, C. (2007). Encouraging the social economy through public policy:

The relationship between the Ontario government and social economy organizations.

Unpublished manuscript.

Brown, S. D., Meinhard, A., Ellis-Hale, K., Henderson, A., \& Foster, M. (2007). Community service and service learning in Canada: A profile of programming across the country [Monograph]. Draft Research Report to the Knowledge Development Centre, Imagine Canada. Brown, S. D., Pancer, S. M., Henderson, A., \& Ellis-Hale, K. (2007). The impact of high school mandatory community service programs on subsequent volunteering and civic engagement [Monograph]. Draft Research Report to the Knowledge Development Centre, Imagine Canada. Canadian Centre for Philanthropy. (2003). NSGVP 2000: The giving and volunteering of youth. Toronto, ON. Retrieved March 2007 from www.givingandvolunteering.ca.

Clandinin, D. J. (2007). Preface. In D. J. Clandinin (Ed.), Handbook of narrative inquiry (pp. ixxvii).

Thousand Oaks, CA: Sage Publications, Inc.

Clandinin, D. J., \& Connelly, F. M. (2000). Narrative inquiry: Experience and story in qualitative research. San Francisco: Jossey-Bass.

Connelly, F. M., \& Clandinin, D. J. (2006). Narrative inquiry. In J. Green, G. Camilli, \& P.

Elmore (Eds.), Handbook of complementary methods in education research (pp. 477-487).

Mahwah, NJ: Erlbaum.

Dewey, J. (2005) Democracy and education. (Original work published in 1916).

Digireads.com. 
Hall, M., Lasby, D., Gumulka, G., \& Tryon, C. (2006). Caring Canadians, involved Canadians: Highlights from the 2004 Canada survey of giving, volunteering and participating No.

71-542-XIE. Ottawa: Ministry of Industry. Retrieved August, 2006 from http:// cansim2.statcan.ca/cgi-win/cnsmcgi.pgm?Lang=E\&SA_Action=Result\&SP_ID=80.

Henderson, A., Brown, S., Pancer, S. M., \& Ellis-Hale, K. (2007). Mandated community service in high school and subsequent civic engagement: The case of the "double cohort" in Ontario, Canada. Journal of Youth \& Adolescence, 1-36.

Livingstone, S. (2006). A snapshot of the 40-hour community involvement program for Ontario high school students in 2006. Unpublished research prepared for the Ontario Network-Canada Volunteerism Initiative. Retrieved February 2007 from www.volunteer.on.ca.

McLeod, L., \& Nicholson, T. (1998, 30 March). Community service lacks supervision. [Electronic Version] College Student Journal, Retrieved February 2007 from www.carleton.ca/jmc/cnews/30031998/story2.html.

Meinhard, A., Foster, M., \& Wright, P. (2006). Re-thinking school-based community service: The importance of a structured program. The Philanthropist, 20(1), 5-22.

Merriam, S. (1998). Qualitative research and case study applications in education. San Francisco: Jossey-Bass.

Metz, E., McLellan, J., \& Youniss, J. (2003). Types of voluntary service and adolescents' civic development. Journal of Adolescent Research, 18(2), 188-203.

Metz, E., \& Youniss, J. (2005). Longitudinal gains in civic development through school-based required service. Political Psychology, 26(3), 413-437.

Ontario Ministry of Education. (1999a). Ontario secondary school, grade 9 - 12 program and diploma requirements. Queen's Printer for Ontario.

Ontario Ministry of Education. (1999b). Policy/Program memorandum no. 124a. Retrieved February 2007 from www.edu.gov.on.ca

Ontario Network Canada Volunteerism Initiative. (2006a). Mandatory community involvement activities....40 hours well spent? (Discussion Paper) Guelph: Ontario Network, Canada Volunteerism Initiative. Retrieved February 2007 from www.volunteer.ca

Ontario Network Canada Volunteerism Initiative. (2006b) Volunteering and mandatory community service: Choice-incentive - coercion-obligation. (Discussion Paper) Volunteer Canada. Retrieved July, 2006 from www.volunteer.ca

Padanyi, P., Meinhard, A., \& Foster, M. (2003). A study of a required youth service program that lacks structure: Do students really benefit? Unpublished manuscript.

Pupo, N. (2004, Spring). Community service: Coercion or volunteerism? CRWS Newsletter, 29, $1-4$.

Taylor, T., \& Pancer, S. M. (2007). Community service experiences and commitment to volunteering. Journal of Applied Social Psychology, 37, 320-345

Barbara Harrison (barbara.a.harrison@gmail.com) is a Joint Phd in Education Candidate at Brock University. Her research interests include a focus on service-learning and community engagement. 
